\title{
PERANCANGAN SISTEM INFORMASI REKAM MEDIS RAWAT JALAN MENGGUNAKAN PENDEKATAN BERORIENTASI OBJEK DI RUMAH SAKIT KHUSUS GIGI DAN MULUT (RSKGM) KOTA BANDUNG
}

\author{
${ }^{1}$ Isnaniah Dzulhajmi ${ }^{2}$ Rini Suwartika Kusumadiarti \\ Politeknik Piksi Ganesha \\ ${ }^{1}$ Program Studi Manajemen Informatika Konsentrasi Informatika Rekam Medis \\ ${ }^{2}$ Program Studi Teknik Informatika Komputer \\ Email : ${ }^{1}$ dzukarya@gmail.com²rinisuwartika@yahoo.com
}

\begin{abstract}
Dental medical records are a systematic document of a patient's dental health history by means of health care. Rumah Sakit Khusus Gigi dan Mulut (RSKGM) Bandung specializing in dental and mouth services is C type Special Hospital, this hospital has been using Hospital Management Information System (SIMRS), but medical record is still in the form of file sheets must be recharged either by the patient who fills the identity, or the doctor / nurse who has completed the examination and action. In addition, the problem that often happens is that the file has been sent to the poly often a mistake in the search, sometimes the file does not exist or has not reached the poly so as to make patients wait long enough in receiving hospital services. This design of outpatient information system using object-oriented approach with depiction using Unified Modeling Language (UML) tool and using PHP programming language and MySQL Database. It is expected that through this design process medical record services can be more effective and efficient
\end{abstract}

Keywords: information system, Outpatient, medical record, PHP.

Abstrak - Rekam medis kedokteran gigi adalah suatu dokumen yang sistematis mengenai riwayat perawatan kesehatan gigi seorang pasien oleh sarana pelayanan kesehatan. Rumah Sakit Khusus Gigi dan Mulut (RSKGM) Kota Bandung yang mengkhususkan diri pada pelayanan gigi dan mulut merupakan Rumah Sakit Khusus tipe C, rumah sakit ini telah menggunakan Sistem Informasi Manajemen Rumah Sakit (SIMRS), namun rekam medis masih berupa lembaran-lembaran berkas yang harus diisi kembali baik oleh pasien yang mengisi identitas, maupun dokter/perawat yang telah selesai melakukan pemeriksaan dan tindakan. Selain itu, masalah yang sering terjadi adalah berkas yang sudah dikirimkan ke poli sering terjadi kesalahan dalam pencarian, 
terkadang berkas tidak ada atau pun belum sampai ke poli sehingga membuat pasien menunggu cukup lama dalam menerima pelayanan rumah sakit. Perancangan sistem informasi rawat jalan ini menggunakan pendekatan berorientasi objek dengan penggambaran menggunakan alat bantu Unified Modelling Language (UML) dan menggunakan bahasa pemrograman PHP dan Database MySQL. Diharapkan melalui perancangan ini proses pelayanan rekam medis dapat lebih efektif dan efisien.

Kata Kunci: information system, Outpatient, medical record, PHP.

\section{PENDAHULUAN}

Rumah sakit sebagai salah satu institusi pelayanan umum membutuhkan keberadaan sistem informasi yang cepat dan akurat serta memadai untuk meningkatkan pelayanannya kepada para pasien. Dalam pencatatan data rekam medis pasien harus dilakukan dengan cepat dan tepat dan data rekam medis ini pun dapat bermanfaat bagi pihak manajemen rumah sakit untuk mengetahui informasi mengenai data yang telah ada. Oleh karena itu, dengan penggunaan sistem informasi yang tepat dan mampu menghasilkan informasi yang cepat dan akurat sesuai dengan kebutuhan sangat dibutuhkan untuk menunjang semua kebutuhan rumah sakit. Pada Rumah Sakit Khusus Gigi dan Mulut (RSKGM) Kota Bandung yang mengkhususkan diri pada pelayanan gigi dan mulut merupakan Rumah Sakit Khusus tipe $\mathrm{C}$, rumah sakit ini telah menggunakan Sistem Informasi Manajemen Rumah Sakit (SIMRS), namun rekam medis masih berupa lembaran-lembaran berkas yang harus diisi kembali baik oleh pasien yang mengisi identitas, maupun dokter/perawat yang telah selesai melakukan pemeriksaan dan tindakan. Selain itu, masalah yang sering terjadi adalah berkas yang sudah dikirimkan ke poli sering terjadi kesalahan dalam pencarian, terkadang berkas tidak ada atau pun belum sampai ke poli sehingga membuat pasien menunggu cukup lama dalam menerima pelayanan rumah sakit. Tujuan penelitian ini adalah untuk menghasilkan suatu sistem informasi rekam medis di Rumah Sakit Khusus Gigi dan Mulut (RSKGM) Kota Bandung untuk menunjang pelayanan yang diberikan kepada pasien.

\section{LANDASAN TEORI}

\section{a. Pengertian Perancangan}

Pengertian perancangan menurut bin Ladjamudin (2005:39) "Perancangan adalah tahapan perancangan (design) memiliki tujuan untuk mendesain sistem baru yang dapat menyelesaikan masalah-masalah yang dihadapi perusahaan yang diperoleh dari pemilihan alternative sistem yang terbaik".

\section{b. Pengertian Sistem}

Pengertian Sistem adalah kumpulan bagian-bagian atau subsistem yang disatukan dan dirancang untuk mencapai suatu sasaran atau tujuan tertentu.

c. Pengertian Data dan Informasi

Menurut Abdul Kadir (2014:44), Data adalah deskripsi tentang benda, kejadian ,aktivitas, dan transaksi yang tidak mempunyai makna atau tidak berpengaruh secara langsung kepada pemakai.

Menurut Sutabri (2012:29), Informasi adalah data yang telah diklasifikasikan atau diinterpretasi untuk digunakan dalam proses 
pengambilan keputusan.

\section{d. Sistem Informasi}

Menurut Turban, McLean, dan Wetherbe (1999:9), Sistem informasi adalah sistem yang dapat didefinisikan dengan mengumpulkan, memproses, menyimpan, menganalisis, menyebarkan informasi untuk tujuan spesifik.

e. UML (Unified Modeling Language)

UML (Unified Modeling Language) adalah bahasa pemodelan untuk sistem atau perangkat lunak yang berparadigma (berorientasi objek). Macam-macam UML (Unified Modeling Language): Use Case Diagram, Class Diagram, Sequence Diagram, State Chart Diagram, Activity Diagram, Component Diagram, Collaboration Diagram, Deployment Diagram.

\section{f. Konsep Rekam Medis}

Menurut Peraturan Menteri Kesehatan Republik Indonesia No. 269/MENKES/PER/III/2008, rekam medis adalah berkas yang berisikan catatan dan dokumen tentang identitas pasien, pemeriksaan, pengobatan, tindakan dan pelayanan lain yang telah diberikan kepada pasien.

Rekam medis kedokteran gigi adalah suatu dokumen yang sistematis mengenai riwayat perawatan kesehatan gigi seorang pasien oleh sarana pelayanan kesehatan. Dokumentasi ini dapat berupa catatan tertulis atau dalam bentuk elektronik, namun harus berisi informasi yang lengkap dan akurat tentang identitas pasien, diagnosa, perjalanan penyakit, kode penyakit ICD-10, proses pengobatan dan tindakan medis serta dokumentasi hasil pemeriksaan (Kemenkes RI, 2015). Rekam medis kedokteran gigi terbagi dalam 4 bagian utama yaitu Identitas pasien, Odontogram, Tabel perawatan, lampiran pelengkap/penunjang: foto x-ray, hasil laboratorium, inform consent, dsb

\section{g. Konsep PHP}

PHP (atau resminya PHP:Hypertext Preprocessor) adalah skrip yang bersifat server-side yang ditambahkan ke dalam HTML. PHP sendiri merupakan singkatan dari Personal Home Page Tools. Skrip ini akan membuat suatu aplikasi dapat diintegrasikan ke dalam HTML sehingga suatu halaman web tidak lagi bersifat statis, namun menjadi bersifat dinamis. Sifat server-side berarti pengerjaan skrip dilakukan di server, baru kemudian hasilnya dikirimkan ke browser (Eko Prasetyo, 2008).

\section{h. Adobe Dreamweaver}

Adobe dreamweaver adalah program yang dibuat untuk menyunting halaman web. Software dreamweaver dikeluarkan oleh Adobe System. Aplikasi ini banyak digunakan oleh para programmer, desain, dan developer web dikarenakan kemudahan dalam penggunan, kelengkapan fitur dan dukungan terhadap teknologi terkini.

\section{METODOLOGI PENELITIAN}

\section{a. Teknik Pengumpulan} Data

a. Observasi

Observasi (pengamatan) merupakan suatu prosedur yang terencana meliputi melihat dan mencatat jumlah dan aktivitas tertentu yang ada hubungannya dengan masalah saat kita teliti (Agus Riyanto, 2011). 
b. Interview (wawancara)

Interview

(wawancara)

merupakan teknik

pengambilan data dimana peneliti mendapatkan keterangan secara lisan dari seseorang (sasaran penelitian) (Agus Riyanto, 2011).

c. Studi Pustaka

Studi pustaka adalah kajian teoritis, referensi serta literatur ilmiah lainnya yang berkaitan dengan budaya, nilai dan norma yang berkembang pada situasi sosial yang diteliti (Sugiyono, 2012).

\section{b. Metode Pengembangan Perangkat Lunak}

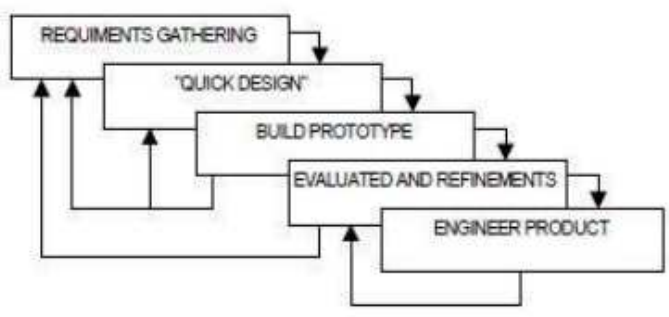

\section{Gambar 1. Metode Prototyping}

Metode pengembangan sistem menggunakan Prototyping, dimana kelebihan metode ini adalah proses pembuatan model sederhana perangkat lunak (software) mengijinkan pengguna memiliki gambaran dasar tentang program di awal.

\section{Hasil Pembahasan}

Perancangan sistem informasi rekam medis rawat jalan menggunakan bahasa pemrograman PHP dan Database MySQL di RSKGM Kota Bandung dikembangkan dengan menggunakan pendekatan berorientasi objek dengan alat bantu perancangan UML (Unified Modelling Language). Perancangan dibuat melalui perancangan input, database, dan output. Perancangan input yang dibuat melalui input data pasien, input pendaftaran pasien rawat jalan, input asesmen medis pasien, input odontogram pasien, input keadaan rongga mulut lainnya, dan input data tabel perawatan pasien. Sedangkan perancangan database-nya adalah data identitas pasien, data pasien rawat jalan, data asesmen medis pasien, data odontogram pasien, data keadaan rongga mulut lainnya, dan data tabel perawatan pasien. Perancangan output yang dihasilkan adalah, rekapitulasi pasien rawat jalan per tanggal, rekapitulasi pasien rawat jalan berdasarkan dokter, dan rekapitulasi pasien rawat jalan per dokter.

\section{a. Perancangan Fungsional Berorientasi Objek}

\section{a. Usecase Diagram}

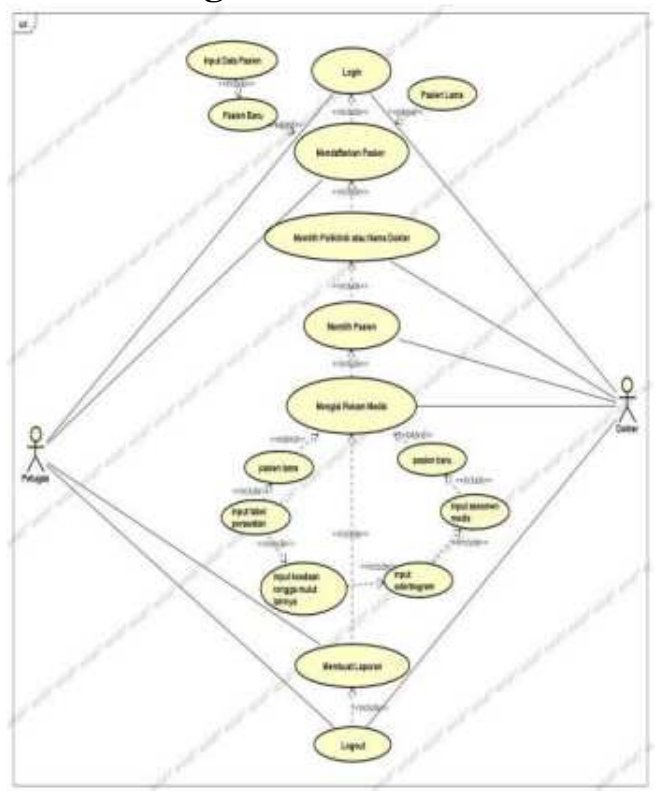

Gambar 2. Usecase Diagram 
b. Activity Diagram Petugas

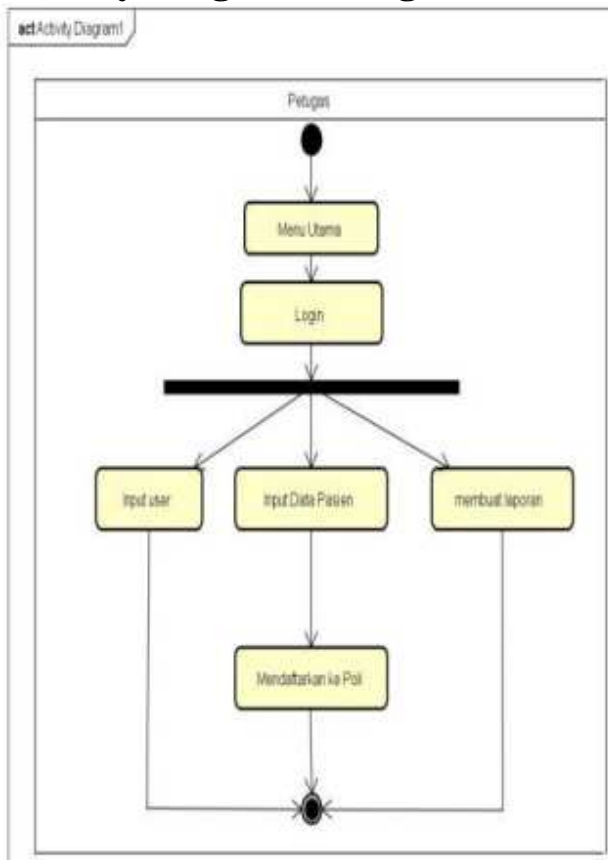

Gambar 3. Activity Diagram

Petugas

\section{c. Activity Diagram Dokter}

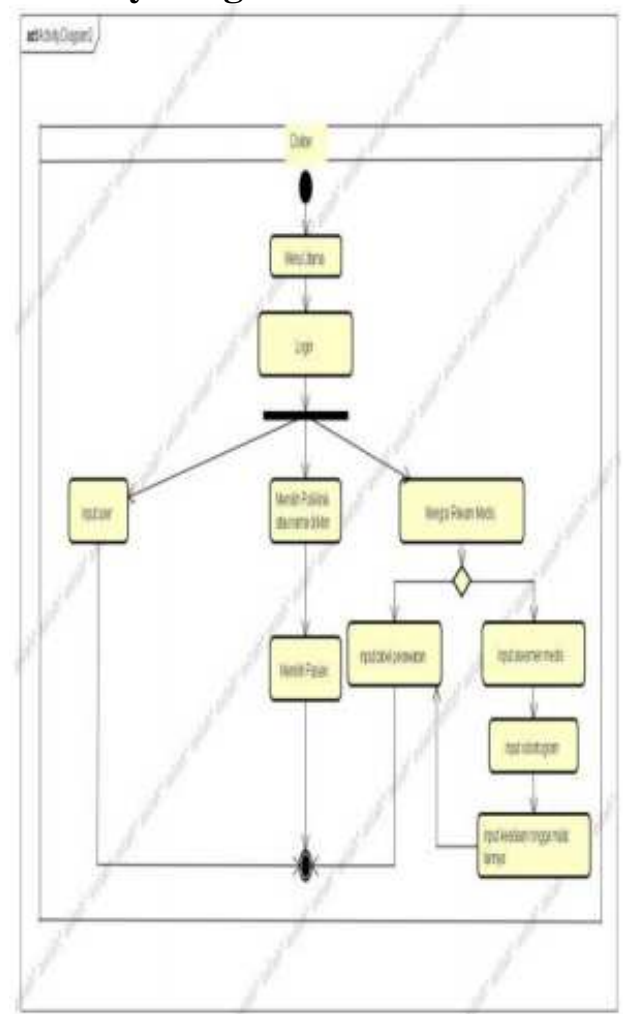

Gambar 4. Activity Diagram

Dokter d. Sequence Diagram Petugas

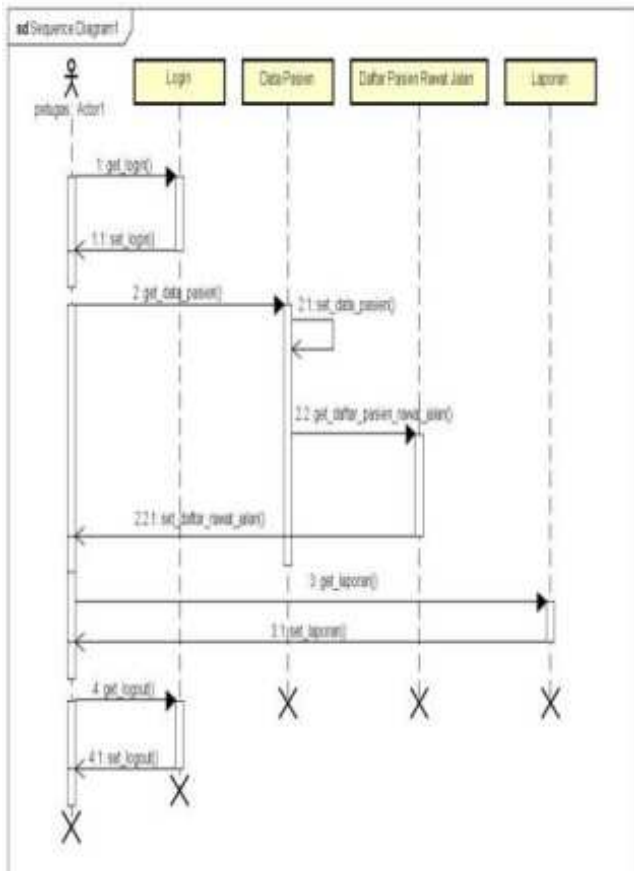

Gambar 5. Sequence Diagram

e. Sequence Diagram Dokter

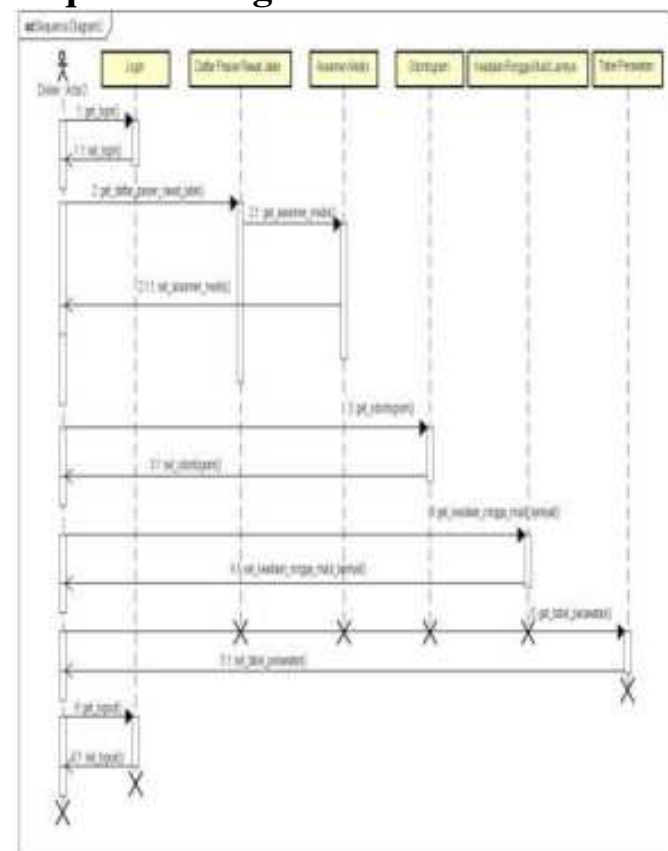

Gambar 6. Sequence Diagram 


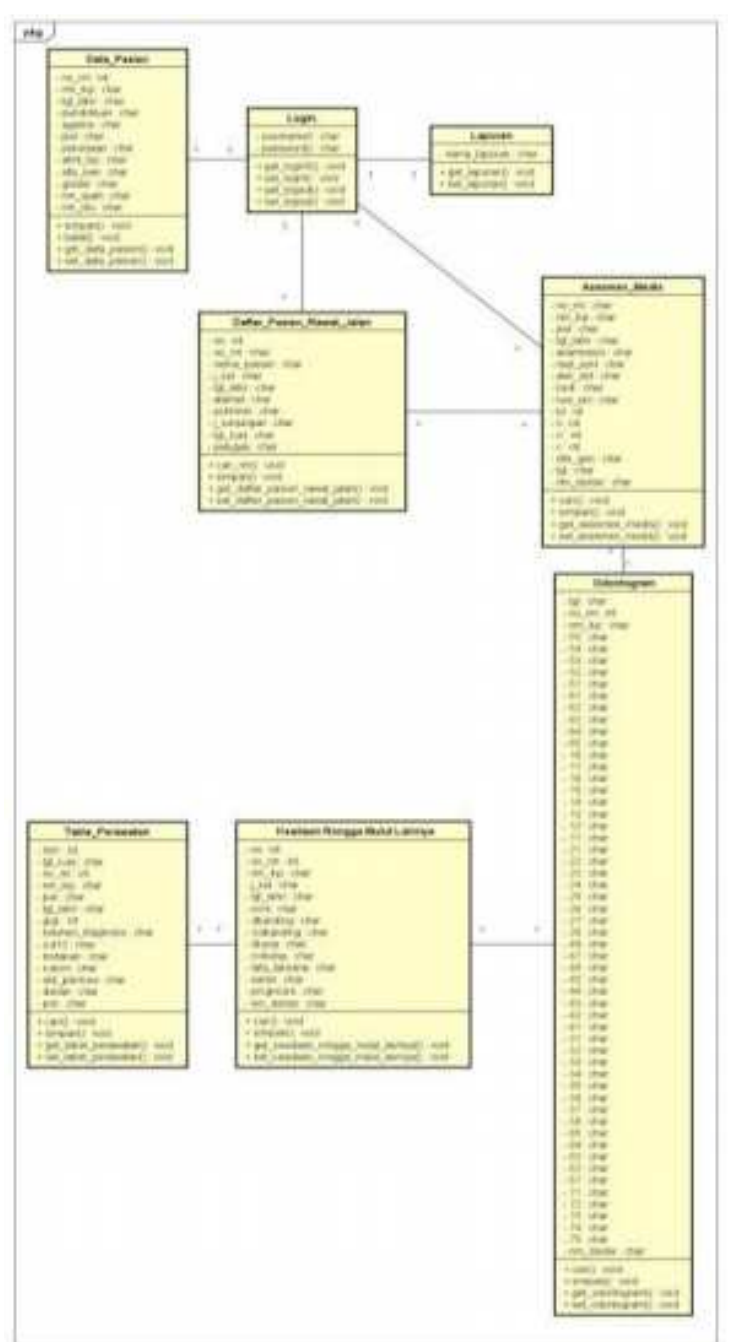

Gambar 7. Class Diagram

\section{b. Implementasi Pemrograman}

c.

\section{a. Halaman Menu Utama}

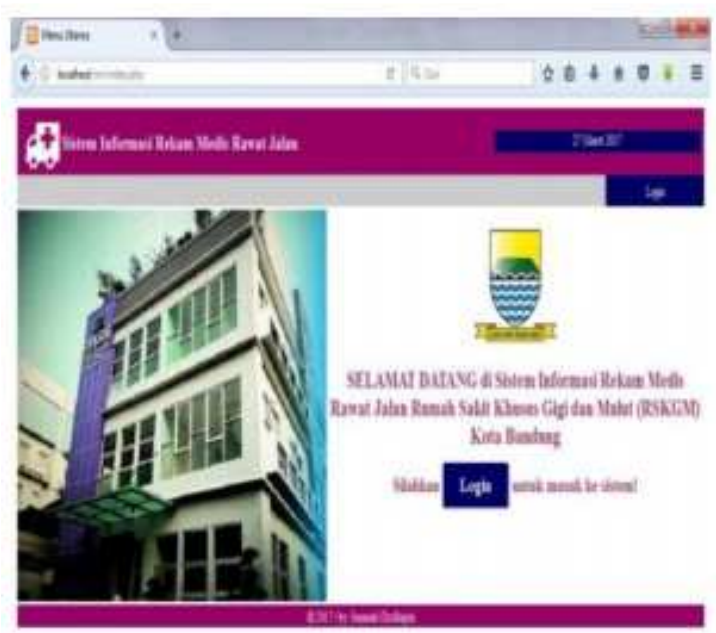

Gambar 7. Halaman Menu Utama

\section{b. Halaman Login}

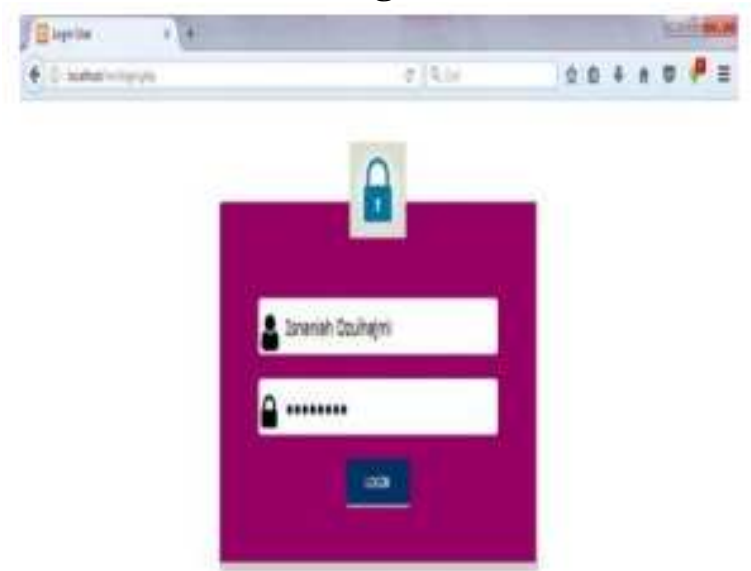

Gambar 8. Halaman Login

c. Halaman Input Data Pasien

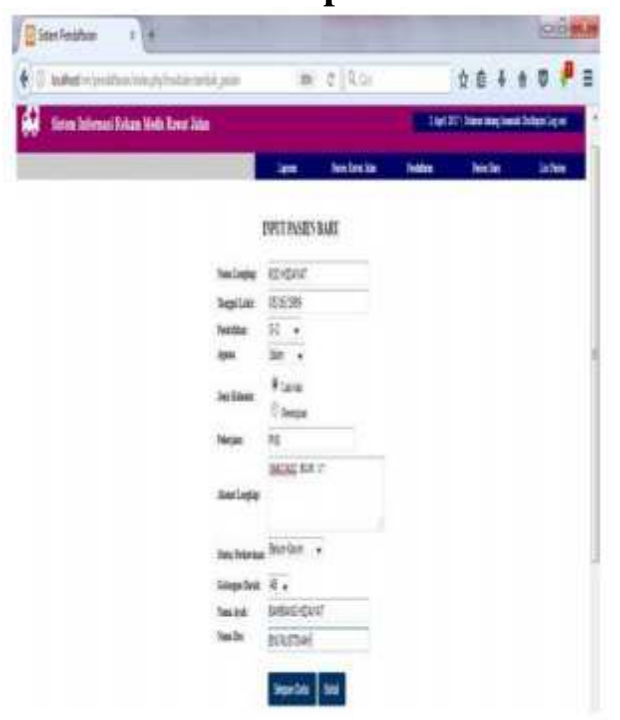

Gambar 9. Halaman Input Data Pasien

d. Halaman Rekapitulasi Pasien Rawat Jalan 


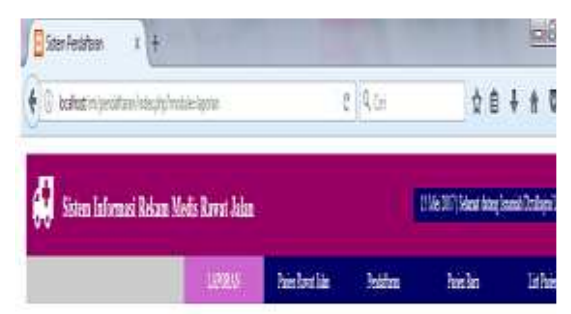

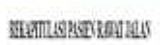
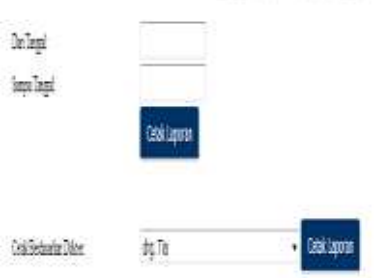

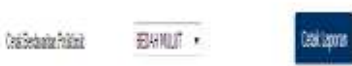

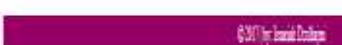

Gambar 10.Halaman rekapitulasi Pasien Rawat Jalan

e. Halaman cetak Rekapitulasi Pasien Rawat Jalan per poliklinik

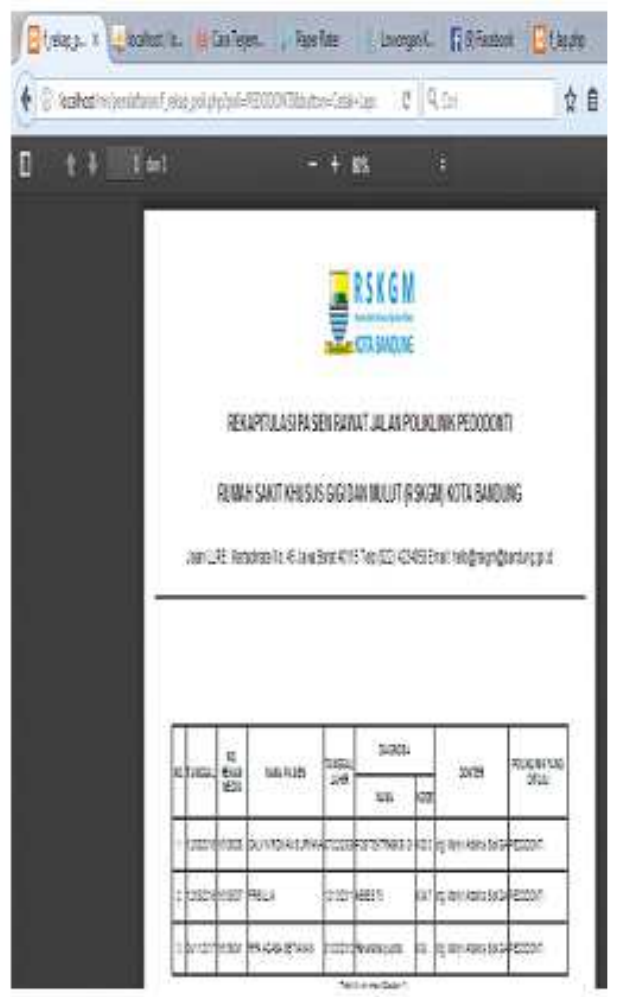

Gambar 11. Halaman cetak Rekapitulasi Pasien Rawat Jalan Per Poliklinik

\section{f. Halaman Odontrogram Pasien}
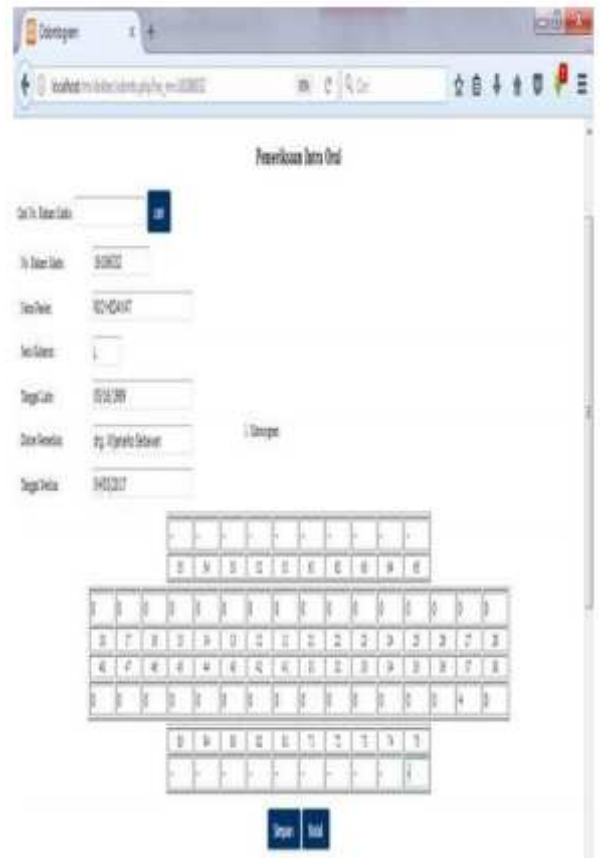

\section{Gambar 12. Halaman} Odontogram Pasien

g. Halaman Tabel Perawatan

\section{Pasien}
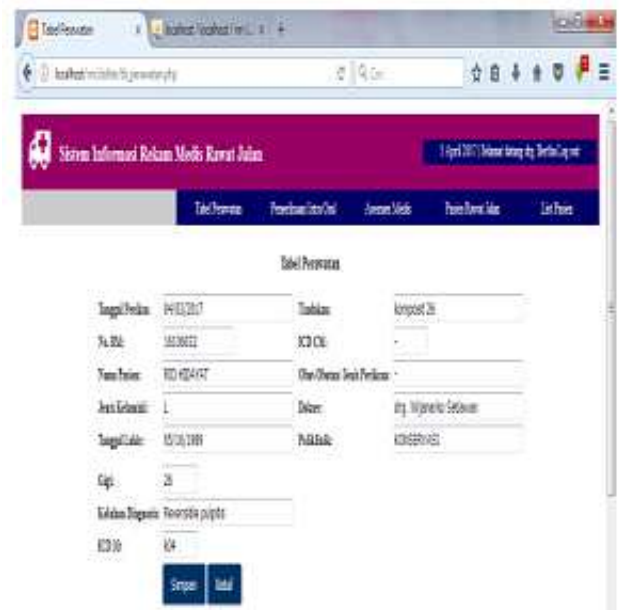

Gambar 13. Halaman Tabel Perawatan Pasien

V. KESIMPULAN DAN SARAN 


\subsection{Kesimpulan}

Berdasarkan penelitian yang dilakukan dapat disimpulkan bahwa pada sebuah Rumah sakit, pelayanan terhadap pasien adalah suatu hal yang sangat penting. Dengan melakukan pengembangan dalam hal pelayanan pasien melalui system komputerisasi diharapkan adanya perubahan yang signifikan sehingga proses pelayanan akan menjadi ebih efektif, efisien dan tepat sasaran.

\subsection{Saran}

Saran yang dapat diberikan sebagai berikut :

a. Memberikan pelatihan kepada pengguna yang akan menggunakan aplikasi ini.

b. Melakukan pemeriksaan keseluruhan oleh ahli di bidang IT untuk mengetahui kekurangankekurangan yang perlu diperbaiki.

c. Melakukan pemeliharaan sistem untuk menjaga sistem dalam keadaan baik

d. Adanya pengembangan program dengan fitur-fitur yang lebih baik lagi.

\section{Daftar Pustaka}

[1] Sukamto dkk. 2012. Sistem Terpadu Rekam Medik Rumah Sakit Dengan Smart Card. Semarang.
[2] Direktorat Jenderal Bina Upaya Kesehatan. 2015. Panduan Rekam Medis Kedokteran Gigi. Jakarta: Kementrian Kesehatan $R I$.

[3] Saputra, Dimas Eka. 2011. Perancangan Sistem Informasi Rekam Medis Berbasis Borland Delphi 7 Di Badan Layanan Umum Daerah Rumah Sakit Ratu Zalecha Martapura. Banjarbaru.

[4] PERATURAN MENTERI KESEHATAN REPUBLIK INDONESIA NO. 1173 TAHUN 2004 tentang rumah sakit gigi dan mulut.

[5] Nugroho Bunafit. 2009. Latihan Membuat Aplikasi Web PHP dan MySQL dengan Dreamweaver MX (6, 7, 2004) dan 8. Yogyakarta: 